\title{
Screening of long-term complications and glycaemic control of patients with diabetes attending Rustenburg Provincial Hospital in North West Province, South Africa
}

\author{
Authors: \\ John M. Tumbo ${ }^{1}$ \\ Faustin N. Kadima ${ }^{1}$ \\ Affilliations: \\ ${ }^{1}$ Department of Family \\ Medicine and Primary Health \\ Care, University of Limpopo, \\ Medunsa, South Africa
}

Correspondence to:

John Tumbo

Email:

tumbo@lantic.net

Postal address:

PO Box 222, Medunsa,

Limpopo, South Africa

\section{Dates:}

Received: 02 Oct. 2011

Accepted: 24 Aug. 2012

Published: 15 Apr. 2013

How to cite this article: Kadima FN, Tumbo JM. Screening of long-term complications and glycaemic control of patients with diabetes attending Rustenburg Provincial Hospital in North West Province, South Africa. Afr J Prm Health Care Fam Med. 2013;5(1), Art. \#375, 5 pages. http://dx.doi.org/10.4102/ phcfm.v5i1.375

\section{Copyright:}

(C) 2013. The Authors. Licensee: AOSIS OpenJournals. This work is licensed under the Creative Commons Attribution License.
Read online:
Background: The prevalence of diabetes mellitus (DM) is increasing worldwide, with more than $90 \%$ being type 2. In South Africa, DM is common amongst all racial groups with the highest prevalence amongst the Indian population (15.8\%), followed by the White (3.5\%) and Black (4.8\%) populations. Long-term cardiovascular, renal, neurovascular and retinal complications of type 2 DM are major causes of disability and mortality - hence the need for screening.

Objective: To describe the screening practices of long-term complications amongst patients with type 2 diabetes attending Rustenburg Provincial Hospital in North West Province (South Africa).

Method: A cross-sectional quantitative study using patients' clinical records was performed. A random sample of 92 out of 1340 patients with type 2 diabetes attending the hospital in 2007 was selected. Demographic information on age, gender, body mass index, residence, level of education, duration of treatment and type of treatment was obtained. The recorded glycosylated haemoglobin $\left(\mathrm{HbA}_{1} \mathrm{c}\right)$, lipids and blood pressure levels were extracted, as well as the results of the dilated eye exam, foot examination, urine test for microalbumin, blood urea and creatinine. The data was analysed using the EPI Info version 6.05 software package.

Results: The screening tests that were carried out consistently included: glycosylated haemoglobin $(95.7 \%)$, blood pressure (100\%), serum glucose (100\%), serum cholesterol $(79.3 \%)$ and serum creatinine (93.5\%). Aspects poorly screened for were: dilated eye examination (19.5\%), foot examination (20.6\%), urine test for micro-albumin (1.1\%), as well as HDL and LDL cholesterol (17.4\%). Abnormal results were mainly detected in: $\mathrm{HbA}_{1} \mathrm{c}(69.3 \%)$, serum creatinine $(30.2 \%)$, dilated eye examination $(38.9 \%)$ and foot examination (52.6\%). The $\mathrm{HbA} 1 \mathrm{c}$ of $9.1 \%$ is far above the target of $6 \%$ and this predisposes patients to long-term complications.

Conclusion: The screening of long-term complications of type $2 \mathrm{DM}$ was poor in most patients and demonstrated a high prevalence of abnormal results. There is a need to improve screening practices.

Dépistage des complications à long terme et le contrôle glycémique des patients diabétiques participant Rustenburg hôpital provincial dans la province du Nord-Ouest, Afrique du Sud

Présentation: La prévalence de diabète non insulinodépendant (DNID) est en hausse dans le monde, plus de $90 \%$ des personnes affectées souffrant d'un diabète de type 2. En Afrique du Sud, le DNID est présent dans tous les groupes raciaux, la prévalence la plus élevée étant observée dans la population indienne $(15,8 \%)$, suivie par les populations blanche $(3,5 \%)$ et noire $(4,8 \%)$. Les complications cardiovasculaires, rénales, neurovasculaires et rétiniennes à long terme du DNID de type 2 sont des causes majeures de handicap et de mortalité, d'où la nécessité de leur dépistage.

Objectif de l'étude: Décrire les pratiques de dépistage des complications à long terme chez les patients souffrant d'un diabète de type 2 et consultant à l'hôpital provincial de Rustenburg, dans la province du Nord-ouest (Afrique du Sud).

Méthode: Une étude transversale quantitative basée sur les dossiers médicaux des patients a été réalisée. Un échantillon aléatoire de 92 patients sur 1340 souffrant de diabète de type 2 et consultant à l'hôpital en 2007 a été sélectionné. Des informations démographiques telles que l'âge, le sexe, l'indice de masse corporelle, le lieu de résidence, le niveau d'éducation, la durée du traitement et le type de traitement ont été obtenues. L'hémoglobine glyquée $\left(\mathrm{HbA}_{1} \mathrm{c}\right)$ enregistrée, les niveaux de lipide et la pression artérielle ont été relevés, ainsi que les résultats de l'examen du fond de l'œil, l'examen des pieds, les analyses d'urine destinées à contrôler les niveaux de microalbumine, d'urée sanguine et de créatinine. Les données ont été analysées à l'aide du logiciel EPI Info version 6.05.

Résultats: Les tests de dépistage réalisés de manière systématique incluaient: l'hémoglobine glyquée $(95,7 \%)$, la tension artérielle $(100 \%)$, le glucose sérique $(100 \%)$, le cholestérol sérique $(79,3 \%)$ et la créatinine sérique $(93,5 \%)$. Les points faisant l'objet d'un dépistage réduit étaient les suivants: l'examen $\mathrm{du}$ fond de l'œil $(19,5 \%)$, l'examen des pieds $(20,6 \%)$, les analyses d'urine afin de détecter le niveau de microalbumine $(1,1 \%)$, ainsi que le cholestérol LHD et le cholestérol LBD $(17,4 \%)$. Des résultats anormaux ont essentiellement été détectés dans les analyses suivantes: $\mathrm{HbA}_{1} \mathrm{c}(69,3 \%)$, créatinine sérique $(30,2 \%)$, examen du fond de l'œil (38,9\%) et examen des pieds (52,6\%). Le taux de HbA1c de 9,1\% est largement supérieur à l'objectif de $6 \%$, ce qui prédispose les patients à des complications à long terme.

Conclusion: Le dépistage des complications à long terme du DNID de type 2 était faible pour la plupart des patients et révélait une forte prévalence de résultats anormaux. Il est nécessaire d'améliorer les pratiques de dépistage. 


\section{Introduction}

Diabetes mellitus (DM) is a major public health problem in both developed and developing countries. ${ }^{1}$ In the USA, DM is a serious disease that affects over 16 million people ( $6 \%$ of the population) and over 150000 people die from the disease and its complications annually. ${ }^{2}$ More than 2 million Canadians are estimated to have DM, where most of these cases are classified as type 2. The economic burden of diabetes and its complications in Canada is estimated to be between 4 and 5 billion US dollar a year. ${ }^{3}$

Similar trends are evident in developing countries south of the Sahara. Type 2 diabetes accounts for well over $90 \%$ of diabetes cases in Sub Saharan Africa, and population prevalence proportions ranged from $1 \%$ in rural Uganda to $12 \%$ in urban Kenya. The reported prevalence of type 1 diabetes was low and ranged from 4 per 100000 in Mozambique to 12 per 100000 in Zambia. The prevalence of gestational diabetes varied from $0 \%$ in Tanzania to $9 \%$ in Ethiopia. Proportions of patients with diabetic complications ranged from $7 \%-63 \%$ for retinopathy, $27 \%$ - $66 \%$ for neuropathy and $10 \%-83 \%$ for microalbuminuria. ${ }^{4}$ In South Africa, the prevalence of diabetes mellitus is about $15.8 \%$ in the Indian population, $3.5 \%$ in the White population and $4.8 \%-6 \%$ in the Black population. ${ }^{5}$

$\mathrm{DM}$ is a group of metabolic diseases characterized by hyperglycemia resulting from absolute or relative deficiency of insulin secretion, insulin action or both, with a fasting plasma glucose $\geq 7 \mathrm{mmol} / \mathrm{L}$ or a plasma glucose $\geq 11 \mathrm{mmol} / \mathrm{L}$ two hours post $75 \mathrm{~g}$ oral glucose load on two or more occasions. ${ }^{6,7,8}$ The chronic hyperglycemia of diabetes mellitus is associated with long-term damage, dysfunction and failure of various organs, especially the eyes, kidneys, nerves, heart and blood vessels. ${ }^{910}$ Type 2 DM, which accounts for $90 \%-95 \%$ of all DM cases, may range from predominant insulin resistance with relative insulin deficiency to predominant insulin secretory defect with insulin resistance, unrestrained hepatic glucose production and other hormonal deficiencies. ${ }^{11,12,13}$

Chronic complications associated with long-term DM are devastating to the sufferers and lead to premature, increased mortality and morbidity. Adults with DM have an annual mortality rate double that of non-diabetic adults. ${ }^{14}$ According to Kalk, DM is responsible for almost 4000 deaths per year in South Africa - most of these deaths are middle-aged people and should be preventable. ${ }^{14,15}$ A study conducted amongst black patients at a primary health care in the public sector of Cape Town showed a high prevalence of DM complications:

- Mean duration of diabetes: 8 (0-28)

- Retinopathy: $55.4 \%$

- Cataracts: $7.9 \%$

- Peripheral neuropathy: $27.6 \%$

- Absent foot pulse: $8.2 \%$

- Amputations: $1.4 \%$

- Persistent proteinuria: 5.2\%.

They concluded that complications from DM are neither identified nor managed well by family physicians. ${ }^{16}$
Studies have shown that most of the complications of DM can be slowed down or even prevented by better management on the part of the health care team, as well as the patient. ${ }^{17,18}$ The complications are minimized through tight glycaemia control and regular screening in accordance with available guidelines. The Society of Endocrinology, Metabolism and Diabetes of South Africa (SEMDSA) developed screening guidelines that recommend tests to de conducted quarterly for glycated haemoglobin (HbA1c), monthly for blood pressure, blood glucose, body mass index and waist circumference measurement, as well as a yearly dilated eye examination, lipid profile, serum creatinine, electrocardiogram and urine test for microablumin. ${ }^{19}$

Bojanala is one of the four districts in North West Province, with about $40 \%$ of the 3.3 million being rural populations. $\mathrm{DM}$ is one of the four top chronic conditions in the Bojanala district, with an estimated prevalence of $19.5 \%$ amongst the adult population. ${ }^{20}$ Rustenburg Provincial Hospital is a 329 bed level 2 public referral hospital serving a population of about 349000 and seeing about 650 patients with diabetes per month - with a high occurrence of complications. In the six months preceding this study, 5 cases of blindness and 4 cases of limp amputation due to DM were identified. ${ }^{20}$ This raised concerns about the screening practices implemented at this hospital and it was the motivation for the conduct of this study.

\section{Aim of the study}

The aim of the study is to describe the screening practices for long-term complications of type 2 diabetes mellitus, such as retinopathy, nephropathy, foot problems and glycaemic control, amongst patients attending Rustenburg Provincial Hospital in North West Province, South Africa.

\section{Significance of the study}

This study will provide baseline data on the screening practices of complications of diabetes that will be a valuable guide for interventions to improve the quality of care of patients and to prevent the complications.

\section{Ethical considerations}

The Research, Ethics and Publications Committee (REPC) of the University of Limpopo (Medunsa Campus) granted ethical approval. The clearance certificate number is MP $107 / 2006$. Permission for accessing patients' records was obtained from the head of the institution. Confidentiality of patients' information was maintained by excluding their names and identifiers.

\section{Methods Design}

A descriptive cross-sectional study that reviewed clinical information contained in patients' records was conducted in 2007. The study population comprised of all patients 
with diabetes attending the hospital outpatient clinic. From the sequentially numbered 1340 files, 92 patient files were systematically selected by taking every 15th file following random identification of the first one between 1 and 15 .

\section{Procedure}

Data collected from patient files included:

- The demographic characteristics: age, sex, residence (urban or rural), level of education and body mass index.

- Level of control recorded: glycaemic control, glycated haemoglobin $\left(\mathrm{HbA}_{1} \mathrm{c}\right)$, lipid (total cholesterol, LDL cholesterol and HDL cholesterol) and blood pressure goals.

- Documented tests and examinations for detection of longterm complications in the previous year: dilated eye exam, comprehensive foot exam and detection of nephropathy through urine dipstick, urine for micro albumin, urea and creatinine.

\section{Analysing}

Data was captured and descriptive analysis performed by a statistician using EPI Info software, version 6.05.

\section{Results}

Records of 92 patients with type 2 DM were reviewed and analysed. In this population, type 2 DM occurs mainly in females $(69.6 \%)$, those aged over forty years $(94.6 \%)$, those with a low education level $(72.7 \%)$ and those living in rural areas (65.2\%) (Table 1). The cut-off age of 40 for type $2 \mathrm{DM}$ was chosen because it is the arbitrary age of distinction between type 1 and type 2 DM. ${ }^{21,22}$

Most of the patients have been living with the disease for less than 10 years. The cut-off duration of 10 years was chosen following the observation that most long-term complications appear after 10 years of living with the disease. ${ }^{23}$ Obesity (either mild or morbid) was common with a prevalence of $42.4 \%$. With regard to treatment, most patients (50\%) were receiving insulin therapy instead of oral anti-diabetic agents $(41.3 \%)$, where $8.7 \%$ received combination therapy.

Screening tests for complications were not preformed consistently. Some screening procedures, such as the dilated eye examination of the retina, was carried out on only $20.1 \%$ of the patients, whilst others, such as glycated haemoglobin and random glucose, were performed as often as $100 \%$ of the time (Table 2). The highest proportion of abnormal results was found in glycated haemoglobin $(70.4 \%)$ and high-density lipoproteins (72\%).

\section{Discussion}

The main finding of the study was the low frequency of screening of long-term complications of DM in the majority of patients, particularly for retinopathy (19.5\%), nephropathy $(1.11 \%)$ and diabetic foot problems $(20.6 \%)$. These are tests that require clinical or technical skills to perform. This study also showed that tests requiring less technical skills,
TABLE 1: Demographic and disease related characteristics.

\begin{tabular}{llll}
\hline Parameter & Categories & N & $\mathbf{\%}$ \\
\hline Age & $<40$ years & 5 & 5.4 \\
& $>40$ years & 87 & 94.6 \\
Sex & Male & 28 & 30.4 \\
& Female & 64 & 69.6 \\
Highest Education & None or Primary & 67 & 72.8 \\
Level & Secondary & 25 & 27.2 \\
& Tertiary & 0 & 0 \\
Residence & Urban & 32 & 34.8 \\
& Rural & 60 & 65.2 \\
Duration of diabetes & $<10$ years & 68 & 73.9 \\
Mellitus disease & $>10$ years & 24 & 26.1 \\
Obesity & Non-obese & 53 & 57.3 \\
& Obese & 33 & 35.9 \\
& Morbid obesity & 6 & 6.5 \\
Treatment modality & Oral anti-diabetic treatment only & 36 & 41.3 \\
& Insulin only & 0 & 0 \\
\hline Total & Combination of insulin and oral treatment & 46 & 50 \\
\hline
\end{tabular}

$N$, Given as number.

TABLE 2: Screening tests for complications.

\begin{tabular}{lcccccc}
\hline Screening test & \multicolumn{2}{c}{$\begin{array}{c}\text { Participants with test } \\
\text { performed }\end{array}$} & & \multicolumn{2}{c}{ Abnormal results } \\
\cline { 2 - 3 } \cline { 6 - 7 } & $\boldsymbol{N}=\mathbf{9 2}$ & $\mathbf{\%}$ & & $\boldsymbol{N}$ & $\mathbf{\%}$ \\
\hline Glycated haemoglobin (HbA1c) & 88 & 95.6 & & 62 & 70.4 \\
Dilated eye exam & 19 & 20.1 & & 7 & 38.8 \\
Comprehensive foot exam & 20 & 21.6 & & 9 & 47.4 \\
Blood pressure & 92 & 100 & & 47 & 50.1 \\
Random glucose & 92 & 100 & & 27 & 29.3 \\
Total cholesterol & 74 & 80.4 & & 19 & 25.6 \\
High density lipoprotein & 25 & 27.1 & & 18 & 72 \\
Low density lipoprotein & 25 & 27.1 & & 5 & 20 \\
Urine for micro albumin & 1 & 1.1 & & 0 & 0 \\
Serum creatinine & 86 & 93.4 & & 26 & 30.2 \\
\hline
\end{tabular}

$N$, Given as number.

such as glycated haemoglobin, blood pressure, random blood glucose, total cholesterol and serum creatinine, were frequently performed and recorded.

Abnormal results were found in 42.1\% (220 out of 522) of all screening tests performed for long-term complications.

Diabetic retinopathy is one of the most prevalent, but preventable causes of blindness. Several randomized controlled trials, such as the DCCT trial, showed that intensive blood glucose control reduced the risk of the progression of diabetic retinopathy by $54 \%$, reduced the development of severe nonproliferative diabetic retinopathy or proliferative diabetic retinopathy by $47 \%$, reduced the need for laser surgery by $56 \%$ and reduced the risk of diabetic macular oedema by $23 \% .{ }^{19}$ Because of the low frequency of screening of retinopathy at $\mathrm{RPH}$ (19 out of 92), it is difficult to draw conclusive inference from this aspect of the study. According to the SEMDSA guidelines, all patients were supposed to have had one retina examination in the previous year.

In the current study, diabetic nephropathy was screened by the means of serum creatinine and microalbuminuria. Using urine for micro albumin level carried out in the past year, the study showed very poor results, since only 1 out 
of the 92 patients $(1.1 \%)$ was screened. Serum creatinine levels were tested in $93.5 \%$ (86 out of 92) of the patients and $30.2 \%$ had results indicative of nephropathy. The presence of microalbuminuria predicts the worsening of renal disease to overt diabetic nephropathy and an elevated risk of cardiovascular disease. ${ }^{24} \mathrm{~A}$ urine test for micro albumin is an essential test that detects early signs of nephropathy, but it was infrequently preformed at this hospital that offered a wide range of primary health care services. A study carried out in a setting in Hungary providing similar services, demonstrated a higher frequency of screening for microalbuminuria. Amongst patients with diabetes in the primary health care system in Hungary, Forkas showed that microalbuminuria was detected in $24.8 \%$ of type 1 DM patients and $25 \%$ of type 2 DM patients. ${ }^{25}$ The study concluded that one third $(33.8 \%)$ of patients with diabetes in a primary care setting exhibited signs or were at risk of renal involvement of diabetes.

Foot complications are common in patients with diabetes and are considered one of the most devastating diabetic complications. The current study showed foot complications were screened in only $20.7 \%$ of participants. Amongst those screened, slightly less than half (47.4\%) had abnormal results. This was much higher than that found at a primary care clinic in Germany, where the prevalence of foot abnormalities was estimated to be $2.9 \%$ in type $2 \mathrm{DM}$ patients with almost $50 \%$ of patients with diabetic foot problems having major and minor amputations. ${ }^{26}$ In Moscow, this prevalence was shown to be $11.22 \%$ in type $1 \mathrm{DM}$ and $5.58 \%$ in type $2 \mathrm{DM}^{27}$.

Complications from diabetes can often be prevented or delayed with good primary care, screening for complications and compliance with the advice from health care providers. ${ }^{17}$ In the current study, the target of $\mathrm{HbA} 1 \mathrm{c}$ was based on the recommendations of SEMDSA and was less than $8 \%{ }^{18}$ This study showed that $95.7 \%$ of patients had their HbA1c tested and a high percentage (69.3\%) had abnormal results (did not achieve glycaemic control). The average HbA1c of $9.1 \%$ of the patients in the study was above the recommendation of SEMDSA $(7 \%-8 \%)$ and this could predispose patients to longterm complications.

\section{Limitations of the study}

The cross-sectional study design allowed the researchers to only obtain a snap shot of the situation regarding screening patterns of long-term complications of type $2 \mathrm{DM}$ at $\mathrm{RPH}$ at that particular time. A prospective study would have been beneficial in capturing information that will help to estimate the prevalence of long-term complications of type $2 \mathrm{DM}$ patients.

The use of patients' records as a source of data could be a limitation because of the poor documentation and the inability to differentiate the stages of complications, such as retinopathy. The results analysed only documented normal and abnormal results without specification of anatomical lesion and severity.
This study focused on the screening practices at a referral hospital. It could not provide information on screening practices at primary health care facilities where the bulk of patients with diabetes and other chronic illnesses are managed.

\section{Conclusion and recommendations}

The screening of long-term complications of type $2 \mathrm{DM}$, such as retinopathy, nephropathy and foot problems, was poor in the majority of patients. The screening tests performed showed a high percentage of abnormal results. The poor screening practices could explain the increase in the late identification of long-term complications. To address this problem in the local context, it is recommended that screening protocols be implemented at all treatment points, that clinicians are trained on the protocols and skills for the screening, and lastly that a quality improvement project be immediately conducted using this data as the baseline.

\section{Acknowledgements}

The authors acknowledge Dr J.M. Kivilu for the statistical support he provided.

\section{Competing interests}

The authors declare that they have no financial or personal relationship(s) that may have inappropriately influenced them in writing this paper.

\section{Authors' contributions}

F.N.K. was involved in the conceptualisation of the study, as well as the collection of data and the writing of the manuscript. J.M.T. was involved in the conceptualisation, data verification and writing of the manuscript.

\section{References}

1. Rheeder P. Type 2 diabetes: The emerging epidemic. S Afr Fam Pract. 2006;48(10):20

2. American Diabetes Association. Screening for type 2 diabetes. Diabetes care. 2000;23:20-23.

3. Harris SB, Petrella RJ, Leadbetter W. Lifestyle interventions for type 2 Diabetes Mellitus. Relevance for clinical practice. Can Fam Physician. 2003;49:1618-1625. PMid:14708927, PMCid:2214163

4. Hall V, Thomsen RW, Henriksen O, Lohse N. Diabetes in Sub Saharan Africa 1999-2011: epidemiology and public health implications. A systematic review. BMC Public Health. 2011 14;11:564.

5. Seedat YK. Implementing the South African hypertensive guidelines in diabetes SAJDVD. 2006;3(2):53.

6. Haslett C, Bonn AN, Chilvers E. Diabetes Mellitus. Davidson's Principles of Medicine. 19th ed. Edinburg: Churchill, 2002; p. 642-682.

7. Huddle KRL. 2005. Practical diabetes management. WITS Diabetes group.

8. Herman WH. Glycaemic control in diabetes. Clinical evidence. BMJ. 1999;319:104106. http://dx.doi.org/10.1136/bmj.319.7202.104, PMid:10398638, PMCid:1116194

9. American Diabetes Association. Screening for type 2 diabetes. Diabetes care. 2000;23:20-23.

10. Mayfield J. Diagnosis and classification of diabetes mellitus: New criteria. Am Acad of Fam Physician; 1998.

11. Rhedeer P. Outpatient diabetes management. University of Pretoria booklet; 2004

12. American Association of Clinical Endocrinologists. Medical Guidelines for Clinical Practice for the Management of Diabetes Mellitus; 2007.

13. Mbokazi AJ \& Ndwamato N. Diabetes mellitus: Chronic complications. CME. 2006;24(10);558-566.

14. Kalk WJ, Pick WM, Sayed AR. Diabetic Mortality in South Africa. SAMJ. 1998;88: 1259-1262. 
15. Levitt NS, Bradshaw D, Zwarenstein MF, Maphumolo S. Audit of public sector primary diabetes care in Cape Town, South Africa: high prevalence of complications,
uncontrolled hyperglycemia, and hypertension. Diabetic Med. 1997;14:1073-1077. http://dx.doi.org/10.1002/(SICI)1096-9136(199712)14:12<1073:AID-DIA498>3.0.CO;2-9

16. Centre for Disease Control and Prevention. National diabetes fact sheet, national estimates and general information on diabetes in the United States. Revised edition. Atlanta, GA; US Department of Health and Human Resources; 1998.

17. Diabetes care. Summary of revisions for the 2005 clinical practice recommendations. ADA. 2005;28:S3.

18. Revised Society for Endocrinology, Metabolism, and Diabetes of South Africa (SEMDSA). Guidelines for diagnosis and management of type 2 diabetes mellitus for primary health care in 2002.

19. DCCT Research Group (1995). The relationship of glycaemic exposure (HbA1c) to the risk of development and progression of retinopathy in the diabetic control and complications trial. Diabetes http://dx.doi.org/10.2337/diabetes.44.8.968

20. Chronic Disease Register. Bojanala District Health Information System; 2007.
21. Ogunbanjo GA. 2006. Type 2 Diabetes: An evidence-based approach to its management by family practitioners. CME 2006;24(10):568-572.

22. American Diabetes Association. Diagnosis and classification of diabetes mellitus. Diabetes care. 2008;31:S55-S60. http://dx.doi.org/10.2337/dc08-S055, PMid:18165338

23. Maberley D, Walker $H$, Koushik A, Cruess A. Screening for diabetic retinopathy in James Bay, Ontario: a cost-effectiveness analysis. CMAJ. 2003;168(1):160-164.

24. Tobe SW, McFarlane PA, Naimark DM. Microalbuminuria in diabetes mellitus. CMAJ. 2002;167(5). PMid:12240818, PMCid:121969

25. Forkas K. Screening of microalbuminuria in diabetic patients in the primary health care system. Orv Hetil. 1997;138(8):459-465.

26. Sämann A, Tajiyeva O, Muller N. Prevalence of the diabetic foot syndrome at the primary care level in Germany: a cross sectional study. Diabetic med. 2001;25(5): 557-563. http://dx.doi.org/10.1111/j.1464-5491.2008.02435.x, PMid:18346154

27. Bakharev IV, Misnikova IV, Dreval AV. Prevalence of diabetic foot syndrome among diabetic patients. European Congress of Endocrinology 2006. Endocrine abstracts 2006;11:339. 